Drying shrinkage of fly ash geopolymeric mortars reinforced with polymer hybrid fibres

Kheradmand, Abdollahnejad and

Pacheco-Torgal

\title{
Drying shrinkage of fly ash geopolymeric mortars reinforced with polymer hybrid fibres
}

Mohammad Kheradmand PhD

C-TAC Research Centre, University of Minho, Guimarães, Portugal

Zahra Abdollahnejad PhD

C-TAC Research Centre, University of Minho, Guimarães, Portugal
Fernando Pacheco-Torgal PhD

Principal researcher, C-TAC Research Centre, University of Minho, Guimarães, Portugal; SHRC, University of Sungkyunkwan, Suwon, Republic of Korea (corresponding author: torgal@civil.uminho.pt)

Drying shrinkage performance is a very important factor for reinforced concrete composites because a high shrinkage performance is associated with a high cracking tendency, which leads to future durability problems. Geopolymeric mortars show much higher drying shrinkage than Portland cement-based composites because they use a low amount of structural water and thus have a higher pore content than ordinary Portland cement composites. Therefore, the use of fibres is especially interesting to counteract the drying shrinkage tendency of geopolymeric mortars. This paper provides results on the restrained and unrestrained shrinkage performance of fly ash-based geopolymeric mortars reinforced with short polymer hybrid fibres (SPHF). The results show that SPHF reduces the shrinkage cracking tendency. A content of SPHF as low as $\mathbf{0 . 0 8 \%}$ was able to reduce the average crack width by four times when compared with non-reinforced mortars. Increasing the content of SPHF from 0.08 to $0.8 \%$ reduces the time of appearance of the first crack by $25 \mathrm{~h}$ and reduces the average crack width by two times.

\section{Introduction}

Geopolymers are alternative materials to ordinary Portland cement (OPC), which are produced through the reaction of an aluminosilicate powder (precursor) with an alkaline activator, usually composed of hydroxide, silicate, carbonate or sulfate, leading to the formation of amorphous aluminosilicate gel and secondary nano crystalline zeolite-like structures (PachecoTorgal, 2014; Provis, 2014; Van Deventer et al., 2010, 2012). These materials have a particular ability for the reuse of several types of wastes (Bernal et al., 2016; Chindaprasirt and Cao, 2014; Payá et al., 2014). This is an important feature, especially in the European context of a circular economy and zero waste target (COM 398 (EC, 2014)) that may lead to an overall savings potential of $€ 630$ billion per year for European industry and can also create more than 180000 direct jobs in the EU by 2030 . Some wastes like fly ash deserve special attention because they are generated in high amounts and have a very low reuse rate. The USA has a reuse rate for fly ash of around $50 \%$, meaning that $30 \mathrm{Mt}$ of fly ash are not reused annually (ACAA, 2016). Other recent works confirm the importance of further studies regarding the development of geopolymers based on fly ash percursors (Zhuang et al., 2016). Shrinkage performance is an important factor for reinforced concrete composites because a high shrinkage performance is associated with a high cracking tendency that leads to future durability problems. Unlike Portland cement hydration, only a small amount of water known as interstitial or structural water' is incorporated into the geopolymer gel production; thus more water is available for evaporation, leading to a higher porosity and causing a large shrinkage deformation (Ranjbar et al., 2016). Several authors (Collins and Sanjayan, 2000b) have confirmed that geopolymers can have much higher shrinkage than Portland cement-based composites, which is due to a much higher mesopore content (82 against $36 \%$ ). Also, more recent investigations have confirmed this pore-related explanation (Mobili et al., 2016). However, geopolymer shrinkage is also dependent on the curing conditions because curing with heat is associated with a lower shrinkage (Wallah and Hardjito, 2014). Recent investigations have shown that slag-fly ash geopolymers with a higher content of slag are associated with higher drying shrinkage (Gao et al., 2016; Lee et al., 2014). This was also confirmed by $\mathrm{Ye}$ and Radlinska (2016) who suggest that shrinkage may be attributed to the structural incorporation of alkali cations in calciumaluminate-silicate-hydrates $(\mathrm{C}-\mathrm{A}-\mathrm{S}-\mathrm{H})$, which reduces the stacking regularity of $\mathrm{C}-\mathrm{A}-\mathrm{S}-\mathrm{H}$ layers and makes it easier for the $\mathrm{C}-\mathrm{A}-\mathrm{S}-\mathrm{H}$ to collapse and become redistributed upon drying. Usually shrinkage performance is assessed through unrestrained shrinkage testing. Assessment of shrinkage using the circular or ellipse restrained ring test is especially interesting for materials that will be used under restrained conditions like repair mortars (Beushausen and Chilwesa, 2013; Khan, 2013; Kristiawan, 2012; Pacheco-Torgal et al., 2015). Collins and Sanjayan (2000a) compared geopolymers and OPC concrete performance with the restrained ring test, reporting that the former cracked after only 1 week of curing, while the latter cracked only after 5 months. Ma and Ye (2015) recently published results comparing the unrestrained and restrained 
Table 1. The major oxides in fly ash

\begin{tabular}{lcccccccc} 
& \multicolumn{1}{c}{ Oxides: wt\% } \\
\cline { 2 - 5 } & $\begin{array}{c}\text { Silicon } \\
\text { dioxide }\end{array}$ & $\begin{array}{c}\text { Aluminium } \\
\text { oxide }\end{array}$ & $\begin{array}{c}\text { Ferric } \\
\text { oxide }\end{array}$ & $\begin{array}{c}\text { Calcium } \\
\text { oxide }\end{array}$ & $\begin{array}{c}\text { Magnesium } \\
\text { oxide }\end{array}$ & $\begin{array}{c}\text { Sodium } \\
\text { oxide }\end{array}$ & $\begin{array}{c}\text { Potassium } \\
\text { oxide }\end{array}$ & $\begin{array}{c}\text { Titanium } \\
\text { dioxide }\end{array}$ \\
\hline Fly ash & 60.81 & 22.68 & 7.64 & 1.01 & 2.24 & 1.45 & 2.7 & 1.46 \\
\hline
\end{tabular}

shrinkage performance of fly ash geopolymer pastes, stating that no cracks were detected. Therefore, the use of fibres is especially interesting to counteract the shrinkage tendency of geopolymer mortars (Ranjbar et al., 2016) also because previous studies show that a strong bond exists between geopolymers and polymer fibres (Bhutta et al., 2017). This paper provides results on the restrained and unrestrained shrinkage performance of fly ash geopolymer mortars reinforced with SPHF.

\section{Experimental programme}

\subsection{Materials}

The raw materials used for the preparation of the geopolymeric mortars were fly ash, calcium hydroxide, sand, sodium silicate, sodium hydroxide $(\mathrm{NaOH})$ and fibres. Sodium hydroxide was obtained from Ercros, SA, Spain, and used to prepare a $12 \mathrm{M}$ sodium hydroxide solution. Distilled water was used to dissolve the sodium hydroxide flakes to avoid the effect of unknown contaminants in the mixing water. The sodium hydroxide mix was made $1 \mathrm{~d}$ prior to use in order to have a homogeneous solution at the time of mortar preparation. The sodium silicate liquid was supplied by Marcande, Portugal. The chemical composition of the sodium silicate was $13.5 \%$ sodium oxide $\left(\mathrm{Na}_{2} \mathrm{O}\right), 58 \cdot 7 \%$ silicon dioxide $\left(\mathrm{SiO}_{2}\right)$ and $45 \cdot 2 \%$ water $\left(\mathrm{H}_{2} \mathrm{O}\right)$. The fly ash was obtained from the Pego thermal power plant in Portugal and classified as class $\mathrm{F}$ according to the ASTM C618 (ASTM, 2015) standard. The chemical composition of the fly ash is presented in Table 1. The loss on ignition is $2.9 \%$. The particle size distribution of the fly ash varied from 2 to $59 \mu \mathrm{m}$ (Figure 1). Fly ash was partially replaced by calcium hydroxide from Lusical H100 to enhance strength (Van Deventer et al., 2012). The sand was provided by Mibal, Minas de Barqueiros, SA, Portugal. Before the use of the sand a sieving operation was carried out to remove dust and coarser particles. Two sieves with a mesh size of 4.75 and $0.6 \mathrm{~mm}$ were used. The size distribution of the aggregates is presented in Figure 2. Two types of fibres (iPlast and iShots) were used to reinforce the geopolymer mortars. The use of those fibres relates to the fact that previous investigations show that they are more effective than monofibres in relation to crack bridging (Pakravan et al., 2017). The fibres used in this study were provided by iSTRiCE (ISTRICE, 2016), Italy (Figures 3 and 4). It should be noted that, as the initial length of the fibres was too long for incorporation into the mortar, it was decided to cut the fibres to a dimension $<8 \mathrm{~mm}$ long.

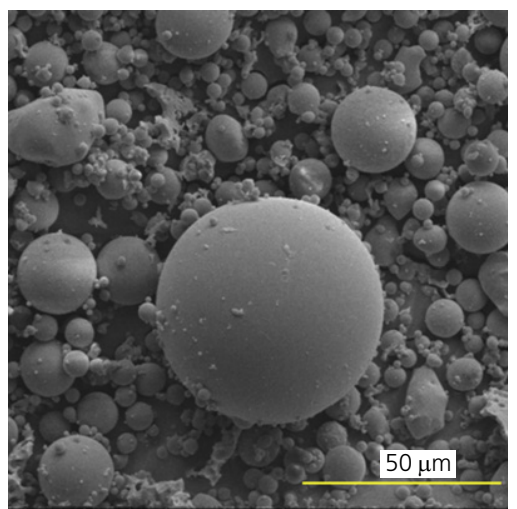

Figure 1. Scanning electron microscopy (SEM) image of fly ash

The detailed characteristics of the hybrid fibres are shown in Table 2.

\subsection{Design and production of mortars}

Four mixtures were studied in relation to water absorption, modulus of elasticity and shrinkage. These included mixtures composed of fly ash $(90 \%$ FA) and $10 \%$ calcium hydroxide activated with a molar activator $(12 \mathrm{M})$ with an activator/ binder ratio of 1.0 and a sodium silicate to sodium hydroxide mass ratio of $2 \cdot 5$. The binder was the sum of fly ash and calcium hydroxide. The composition of the mortars is shown in Table 3. Four fibre contents $(0,0 \cdot 08,0 \cdot 2$ or $0 \cdot 8 \%)$ by weight of binder were used. The mortars incorporate a combination of two fibres that were used in equal mass quantity $(50 \%$ iPlast-50\% iShots). Sodium hydroxide was mixed with sodium silicate solution to dissolve the silica and alumina of the fly ash particles, resulting in a homogenised gel lasting $1 \mathrm{~min}$; next, all the solid material was mixed by using a standard mixture following speed I $(65 \mathrm{r} / \mathrm{min})$ for $3 \mathrm{~min}$; this was followed by the addition of the activator into the mixture, which was then run for $1 \mathrm{~min}$ at speed $\mathrm{I}(65 \mathrm{r} / \mathrm{min})$ and another $1 \mathrm{~min}$ at speed II $(90 \mathrm{r} / \mathrm{min})$. The mixture for the unrestrained shrinkage test was transferred to metallic moulds that were cured under laboratory conditions with a temperature of about $25^{\circ} \mathrm{C}$ and $65 \%$ relative humidity. After $\approx 24 \mathrm{~h}$ the specimens were demoulded and kept sealed with plastic wrap and then left under the same curing conditions until the date of testing. For the testing of modulus of elasticity, the cylindrical 


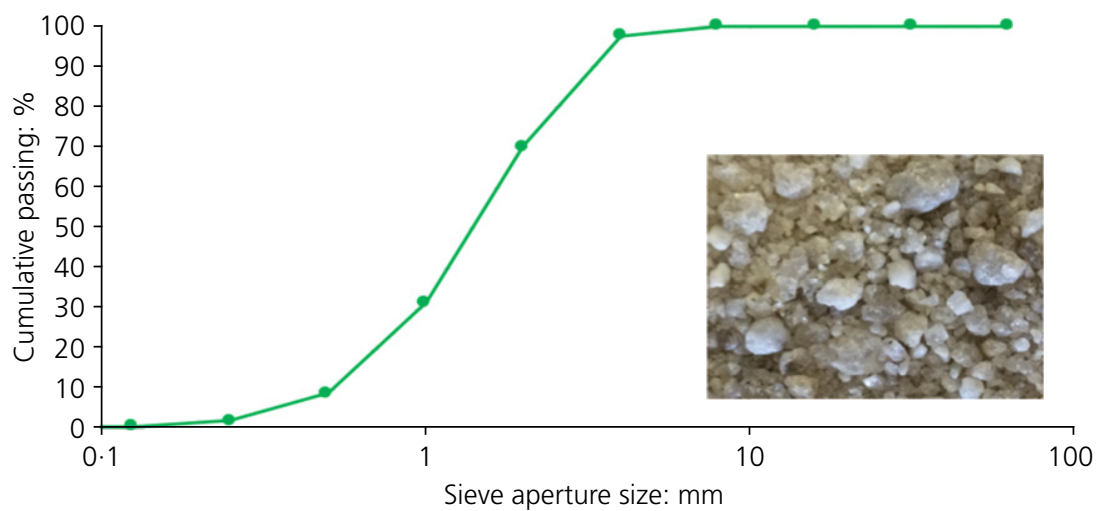

Figure 2. Particle size characteristics of the sand material

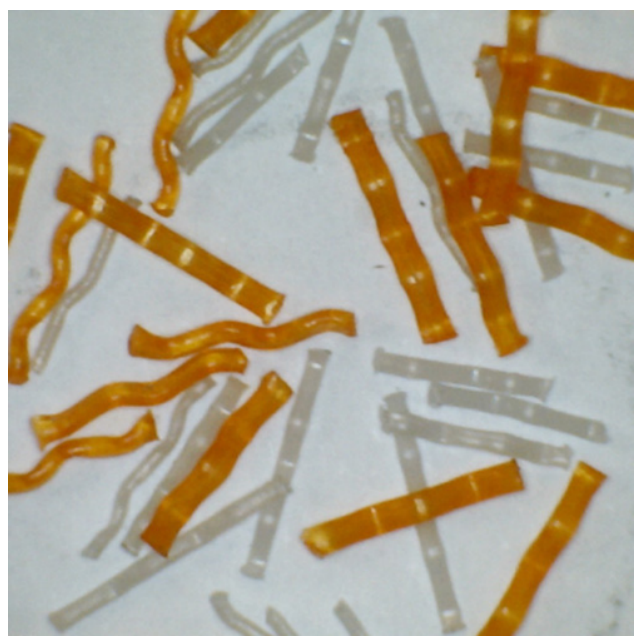

Figure 3. Image of the hybrid fibres: iPlast (in grey colour) and iShots (in orange/dark-grey colour). A full-colour version of this figure can be found on the ICE Virtual Library (www. icevirtuallibrary.com)

specimens (with diameter of $88 \mathrm{~mm}$ and length of $170 \mathrm{~mm}$ ) were kept sealed by using plastic wrap and cured under laboratory conditions with heat for a testing time of $28 \mathrm{~d}$. In the case of restrained shrinkage, the mixture was transferred to a special elliptical mould. Then, it was placed on the standard vibration table for $2 \mathrm{~min}$. The specimens were kept sealed by using plastic wrap and they were cured under laboratory conditions with temperatures of $20 \pm 3^{\circ} \mathrm{C}$ and $70 \% \pm 10 \%$ relative humidity. After $24 \mathrm{~h}$ the specimens' outer ellipse ring was removed and then left under the same curing conditions, and the test was then immediately started by monitoring the appearance of cracking on the tested specimens for $14 \mathrm{~d}$
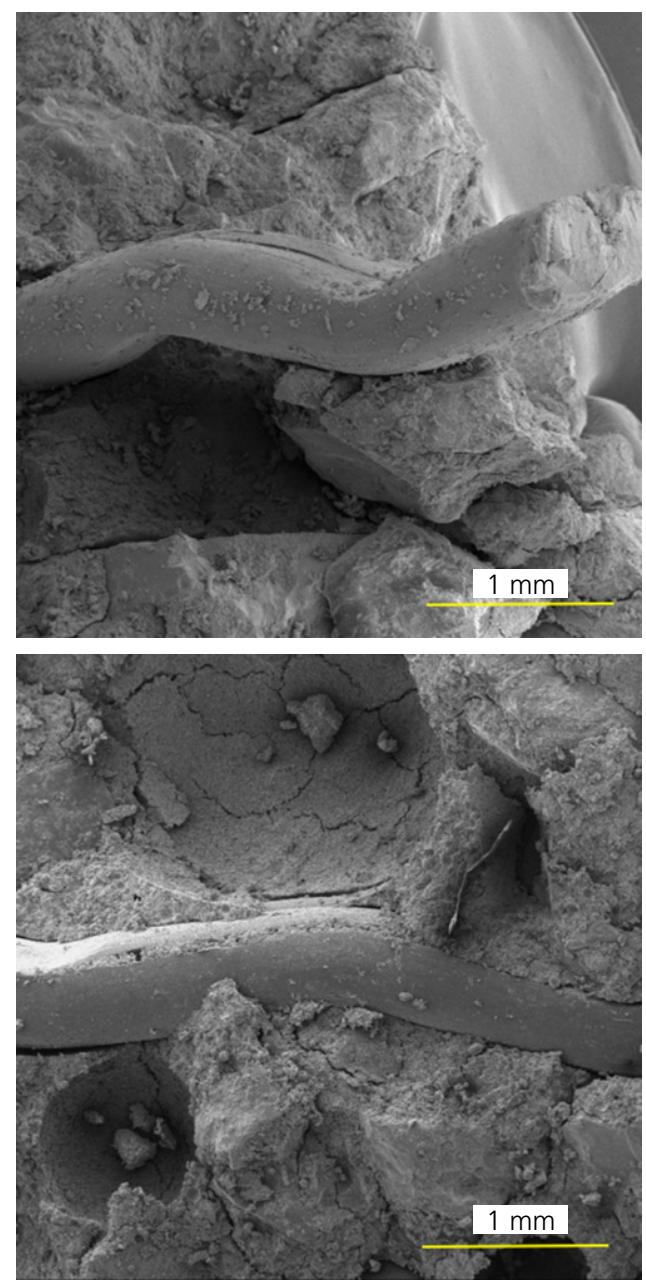

Figure 4. Low-resolution SEM image of hybrid fibre in the mortar 
Table 2. Properties of the fibres (ISTRICE, 2016)

\begin{tabular}{llllccccc}
$\begin{array}{l}\text { Fibre } \\
\text { name }\end{array}$ & Composition & Geometric shape & Colour & $\begin{array}{c}\text { Initial } \\
\text { length: } \\
\mathbf{m m}\end{array}$ & $\begin{array}{c}\text { Diameter: } \\
\mathbf{m m}\end{array}$ & $\begin{array}{c}\text { Specific } \\
\text { weight: } \\
\mathbf{k g} / \mathbf{d m}\end{array}$ & $\begin{array}{c}\text { Ultimate } \\
\text { strength: } \\
\mathbf{M P a}\end{array}$ & $\begin{array}{c}\text { Elastic } \\
\text { modulus: } \\
\mathbf{G P a}\end{array}$ \\
\hline iPlast & Polymer & Monofilament/macro & Grey & 29 & 0.55 & 1.0 & 520 & $4 \cdot 1$ \\
iShots & Polymer & Monofilament/macro & Orange & 49 & 0.79 & 1.0 & 520 & $4 \cdot 1$
\end{tabular}

Table 3. Composition of the alkali activated cement based binder (AACB) mortars

\begin{tabular}{lcccccc} 
& \multicolumn{5}{c}{ Materials: $\mathbf{k g} / \mathbf{m}^{\mathbf{3}}$} \\
\cline { 2 - 7 } Sample name & FA & CH & SA & SS & SH & HF \\
\hline 90FA_10CH_12M_2.5S/H_1.0A/B_0.0HF & $415 \cdot 8$ & $46 \cdot 2$ & $1385 \cdot 9$ & $329 \cdot 5$ & $132 \cdot 4$ & 0 \\
90FA_10CH_12M_2.5S/H_1.0A/B_0.08HF & $415 \cdot 5$ & $46 \cdot 1$ & $1385 \cdot 1$ & $329 \cdot 3$ & $132 \cdot 3$ & $0 \cdot 6$ \\
90FA_10CH_12M_2.5S/H_1.0A/B_0.2HF & $415 \cdot 1$ & $46 \cdot 1$ & $1383 \cdot 9$ & $329 \cdot 1$ & $132 \cdot 2$ & $1 \cdot 4$ \\
90FA_10CH_12M_2.5S/H_1.0AB_0.8HF & $413 \cdot 4$ & $45 \cdot 9$ & $1378 \cdot 1$ & $327 \cdot 7$ & $131 \cdot 7$ & $5 \cdot 7$
\end{tabular}

FA, fly ash; $\mathrm{CH}$, calcium hydroxide; SA, sand; SS, sodium silicate; SH, sodium hydroxide; HF, hybrid fibres

(through visual observation). The specimen was checked regularly during this period in order to identify the crack formation on the surface of the specimen.

\subsection{Test procedures}

\subsubsection{Modulus of elasticity}

The determination of the modulus of elasticity was conducted in a compression test according to the European standard EN 12390-13 (CEN, 2014). Twenty four hours prior to testing, cylinders were capped using a stabiliser compound which provided a smooth surface for the platen to make contact and reduced the variability between compression specimens. Three cylinders from each mixture were tested under a $100 \mathrm{kN}$ capacity testing frame (Figure 5). A computer software controlled the load rate and collected data for the applied force. Three linear variable differential transformers (LVDTs) were attached to a compressometer and wired to the data acquisition system and computer software as standard strain gauges. Two rings were placed at a heights of one-third and two-thirds of the global height of the cylinder, of which the axis distances between the rings were considered fixed at $60 \mathrm{~mm}$ through all the tests. Three LVDTs

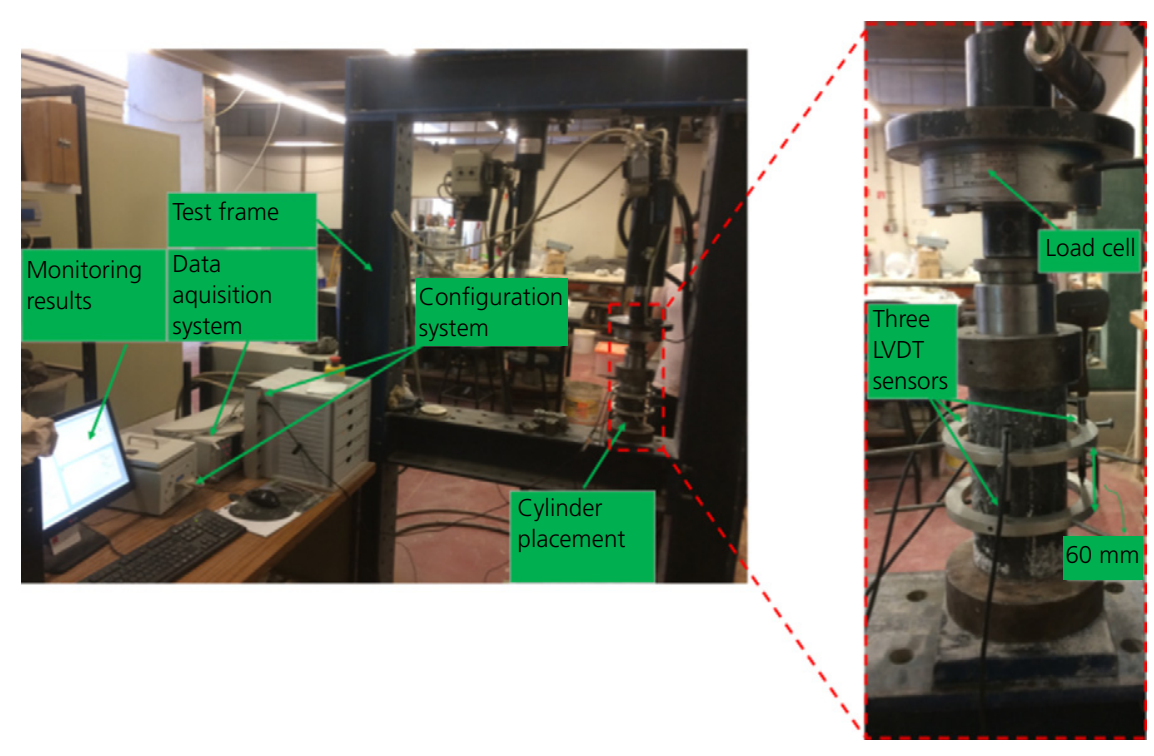

Figure 5. Modulus of elasticity test frame 


\begin{tabular}{|c|c|}
\hline Placement & Dimension: $\mathrm{mm}$ \\
\hline Outer ellipse ring long axis & 600 \\
\hline Outer ellipse ring short axis & 240 \\
\hline Inner ellipse ring long axis & 560 \\
\hline Inner ellipse ring short axis & 200 \\
\hline Height & 80 \\
\hline
\end{tabular}

Figure 6. Ellipse ring test set-up (with dimensions of the ellipse mould)

were attached on the top ring, being free to rotate on the horizontal surface of the bottom ring. A loading cycle of $40 \%$ of the ultimate stress was used, to obtain the equation of the straight line in the elastic zone. Data for load and displacement were acquired automatically by the computer software, and the modulus of elasticity of each specimen was calculated as the average of the three slopes of the stress-strain curves.

Table 4. Modulus of elasticity of the AACB mortars

\begin{tabular}{|lc} 
Formulation & $\begin{array}{c}\text { Modulus of } \\
\text { elasticity: GPa }\end{array}$ \\
\hline 90FA_10CH_12M_2.5S/H_1.0A/B_0.0HF & $4 \cdot 6$ \\
90FA_10CH_12M_2.5S/H_1.0A/B_0.08HF & $4 \cdot 7$ \\
90FA_10CH_12M_2.5S/H_1.0A/B_0.2HF & $5 \cdot 1$ \\
90FA_10CH_12M_2.5S/H_1.0A/B_0.8HF & $6 \cdot 2$ \\
\hline
\end{tabular}

\subsubsection{Unrestrained drying shrinkage}

For unrestrained drying shrinkage, mortar prisms of dimensions $40 \mathrm{~mm} \times 40 \mathrm{~mm} \times 160 \mathrm{~mm}$ were used. Demoulding was conducted after $24 \mathrm{~h}$ and then the length change testing procedure started from this age as per ASTM C490 (ASTM, 2000) standard up to $28 \mathrm{~d}$. The specimens were cured under control room conditions at $20 \pm 3^{\circ} \mathrm{C}$ and $70 \% \pm 10 \%$ relative humidity. In order to calculate the length change of the specimens, each type of specimen was placed into an apparatus model Mahr-MarCator 1075R. A dimensionless parameter $L$ was introduced to evaluate the effect of controlled curing on the mass loss percentage, as follows

$$
\text { 1. } L=\frac{\Delta w}{w_{0}}
$$

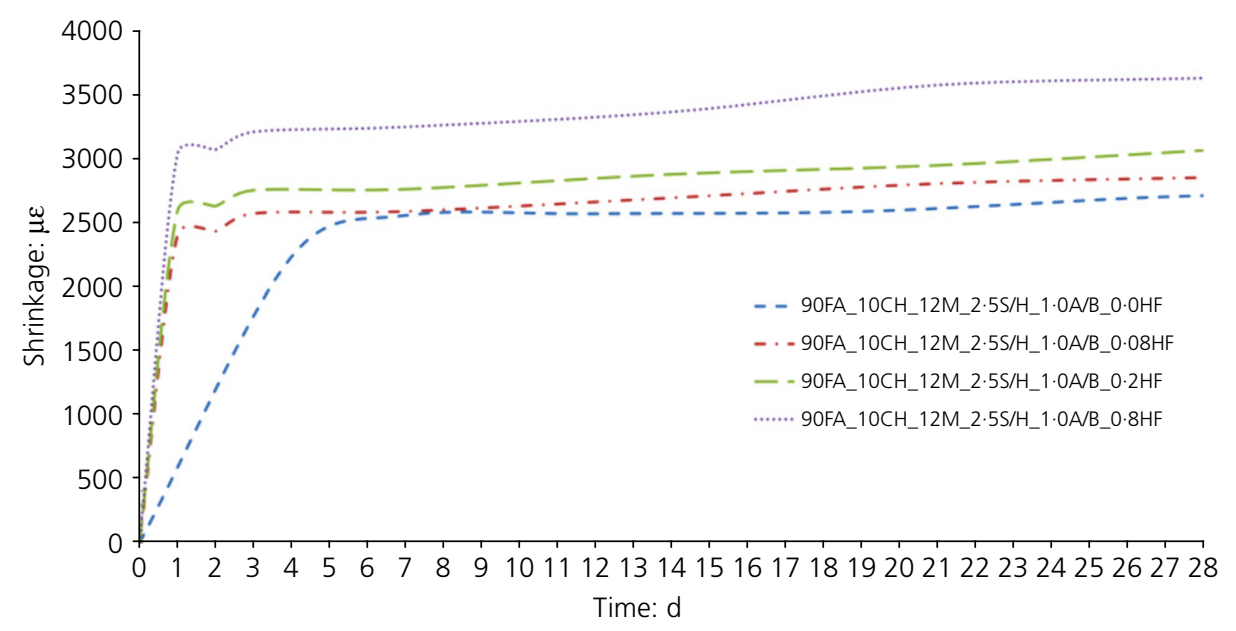

Figure 7. Unrestrained shrinkage behaviour of mortars with different hybrid fibre content 
where the $\Delta w$ is the increment of weight loss, and $w_{0}$ is the initial weight of the specimen.

\subsubsection{Restrained shrinkage}

Restrained shrinkage tests were conducted using an ellipse ring test through visual observation and monitoring for the development of cracking. The dimensions of the ellipse ring
(Figure 6) test were the same as those used recently by Ma and Ye (2015).

\section{Results and discussion}

\subsection{Modulus of elasticity}

The results of the modulus of elasticity are shown in Table 4. The increase in the SHPF from 0.08 to $0.8 \%$ leads to an

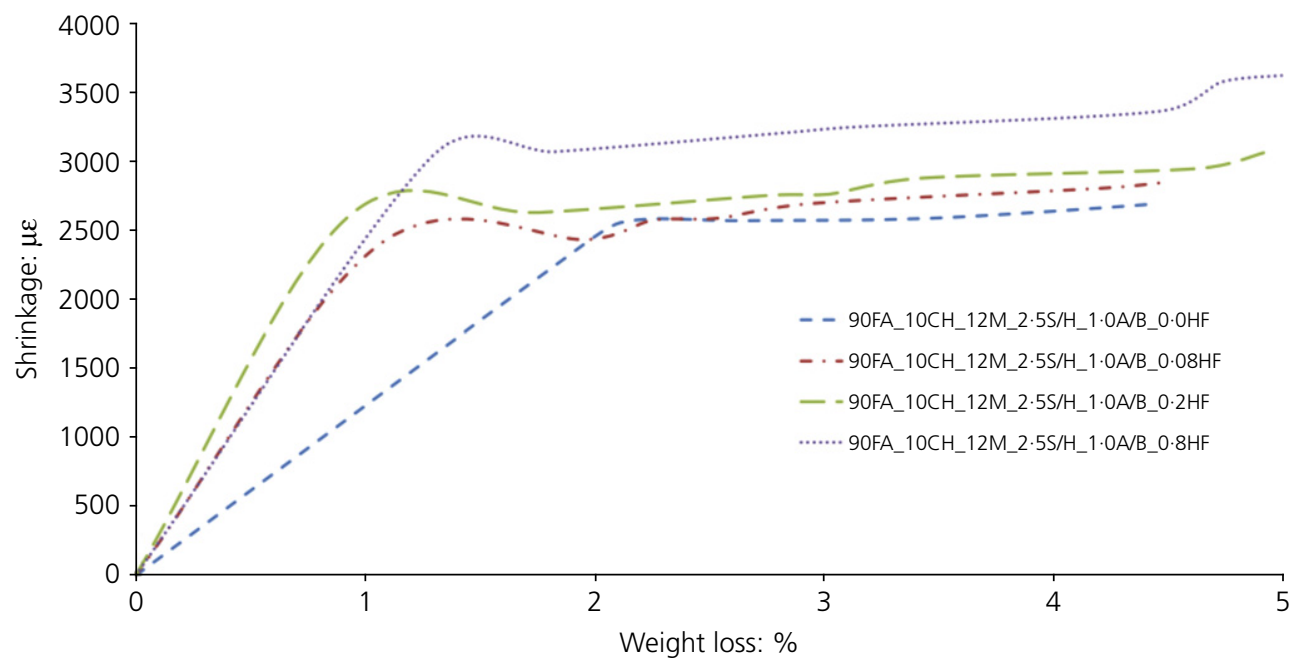

Figure 8. Unrestrained shrinkage plotted against weight loss for mortars with different hybrid fibre content

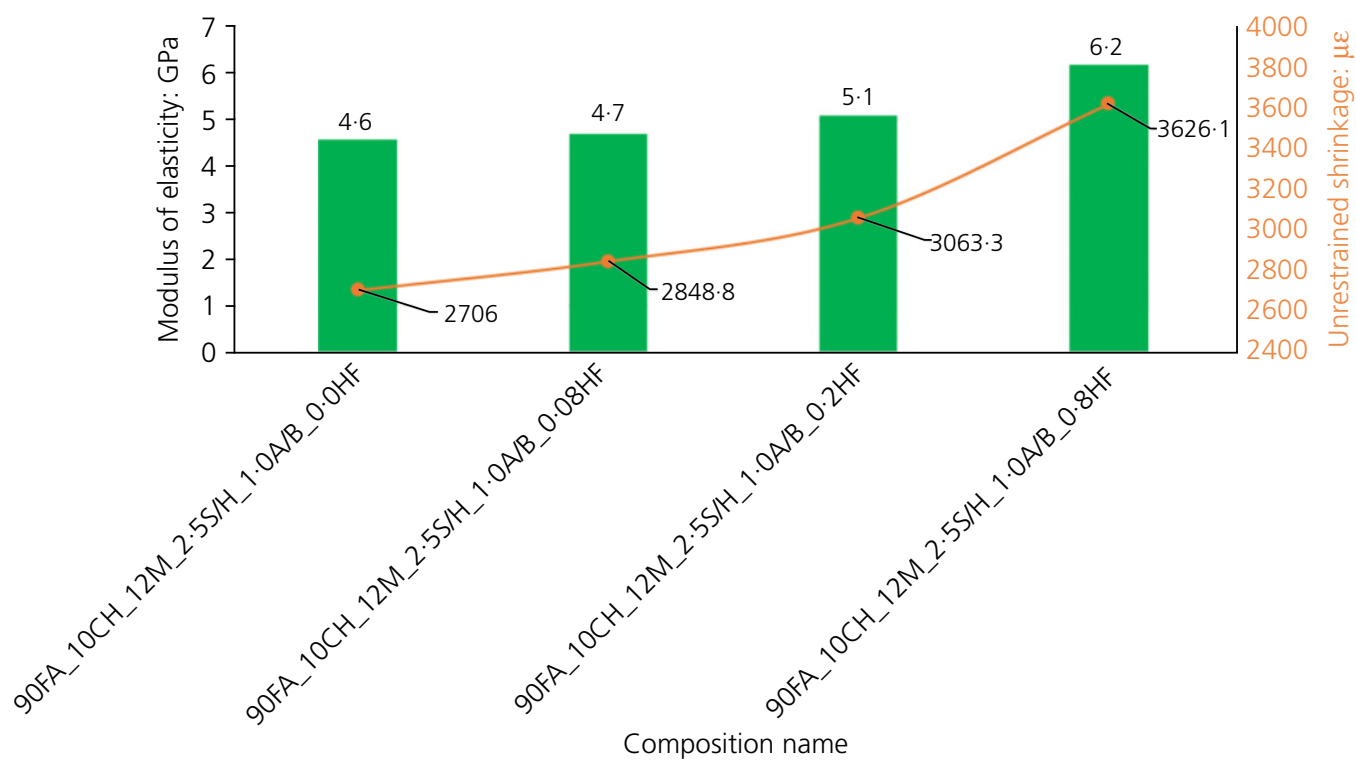

Figure 9. Relationship between ultimate value of unrestrained shrinkage and the modulus of elasticity for mortars with different hybrid fibre content. A full-colour version of this figure can be found on the ICE Virtual Library (www.icevirtuallibrary.com) 
increase of the modulus of elasticity of around 30\% from 4.7 to $6 \cdot 2 \mathrm{GPa}$. This SHPF has a modulus of elasticity that is around $10 \%$ lower than the non-reinforced geopolymeric mortar, so it would be expected that an increase in the fibre content could be associated with a slight reduction on the reinforced geopolymeric mortars. This may be associated with the fact that under compression the presence of SHPF may have a delayed cracking effect.

\subsection{Unrestrained drying shrinkage}

Figure 7 shows the results of the unrestrained shrinkage. The addition of SHPF is associated with an increase in unrestrained shrinkage from $2500 \mu \varepsilon$ for the non-reinforced mortar mixture up to $3500 \mu \varepsilon$ for the mixture with the high SHPF content. These results can be explained not only by the patterns of water evaporation (Figure 8) but also by the performance of the modulus of elasticity for the different mixtures (Figure 9). This is in agreement with the results reported by others (Mobili et al., 2016). Also Ranjbar et al. (2016) recently reported that the use of a content of $5 \%$ of polypropylene fibres caused increased unrestrained shrinkage due to an increase in pore volume.

\subsection{Restrained shrinkage}

\subsubsection{Crack initiation and propagation}

Cracks were carefully monitored across the outer circumferential surface, alongside the top surface of the thin elliptical ring specimen. Figure 10 shows the crack positions in the thin elliptical ring specimen and the wall of the plain mortar with formulation of 90FA_10CH_12M_2.5S/H_1 $0 \mathrm{~A} / \mathrm{B} \_0 \cdot 0 \mathrm{HF}$.

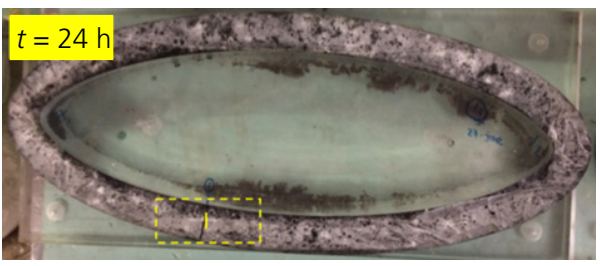

(a)

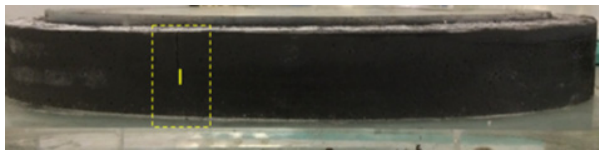

(b)

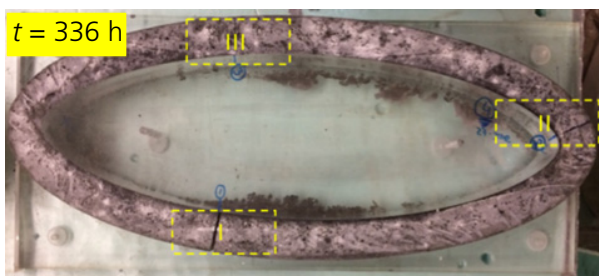

(c)
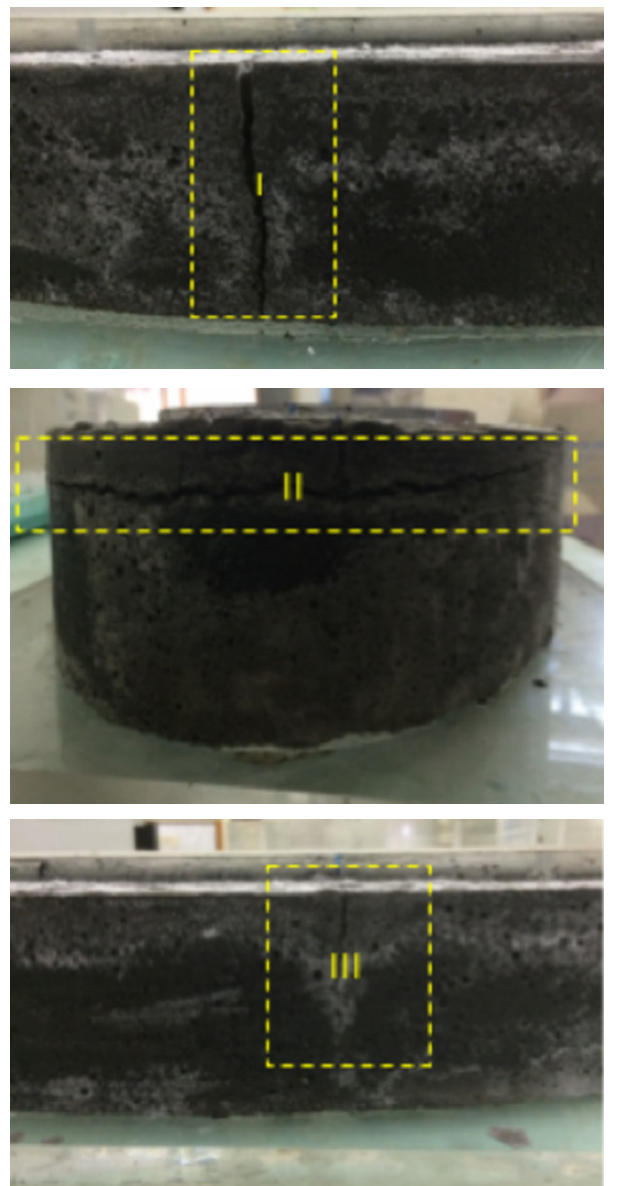

(d)

Figure 10. Crack positions in thin elliptical ring for mixture 90FA_10CH_12M_2.5S/H_1.0A/B_0.0HF: (a) top view of the crack position at the initial time of crack appearance; (b) lateral view of the initial crack position; (c) top view of the crack positions at the final time of test; (d) lateral view of the final crack positions composed of three different crack placements 
Kheradmand, Abdollahnejad and

Pacheco-Torgal

\section{Offprint provided courtesy of www.icevirtuallibrary.com Author copy for personal use, not for distribution}

As observed, the crack originally initiated at I along the height of the wall at a time of $24 \mathrm{~h}$. Then, the cracks of II and III appeared, but crack III ceased to propagate due to reduced crack-driving energy. However, as a result of increased circumferential tensile stress redistribution in other regions of the mortar, cracks were propagated at I and II. However, as a result of increased stress in II, it developed in the radial direction of the ring; possibly this was due to the presence of a moisture gradient (Weiss and Shah, 2002). The suggested crack may initiate at the outer surface and propagate towards the inner one. The influence of SHPF on the crack pattern is shown in Figures 11-13. Figures 11 and 12 indicate that the initial crack was observed at $t=30 \mathrm{~h}$ and $t=40 \mathrm{~h}$ at the region labelled as 'I', for the mortar with formulation of 90FA_10CH_12M_2.5S/H_1.0A/B_0.08HF and 90FA_10CH_ 12M_2.5S/H_1.0A/B_0.2HF, respectively. In both cases, the crack originally initiated at $\mathrm{I}$ along the height axis due to

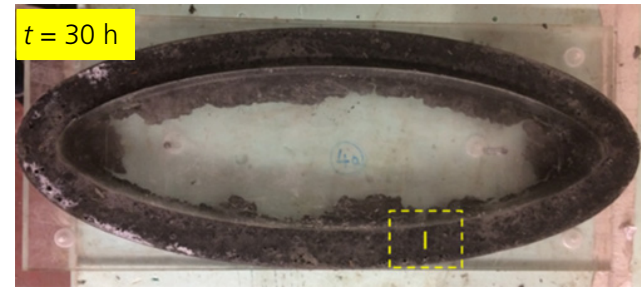

(a)

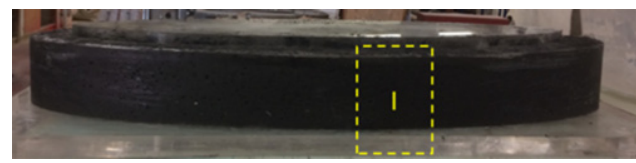

(b)

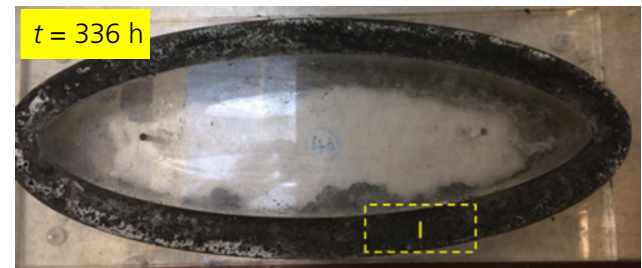

(c)

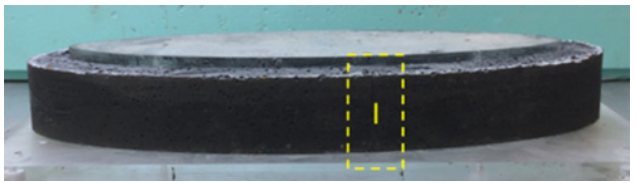

(d)

Figure 11. Crack positions in thin elliptical ring for the mixture 90FA_10CH_12M_2.5S/H_1.0A/B_0.08HF: (a) top view of the crack position at the initial time of crack appearance; (b) lateral view of the initial crack position; (c) top view of the crack positions at the final time of test; (d) lateral view of the final crack positions composed of one visible crack placement the stress concentration. However, such a crack did extend through the height of the wall of the mortar during the $14 \mathrm{~d}$ of monitoring. Figure 12 indicates the initial crack appearance that was observed in the thin elliptical ring specimens with 90FA_10CH_12M_2.5S/H_1.0A/B_0 2HF that occurred almost at the same position as those that already occurred for the mortar with formulation of 90FA_10CH_12M_2.5S/ H_1.0A/B_0.08HF. As shown in Figure 13, there is a notable crack on the outer circumferential surface near the principal axis of the thin elliptical ring for the mortar with formulation of 90FA_10CH_12M_2.5S/H_1.0A/B_0 $8 \mathrm{HF}$. It is interesting to note that the crack that initiated (at a time of $72 \mathrm{~h}$ ) was propagating through the mortar ring wall until $14 \mathrm{~d}$ of monitoring, whereas, in the plain mortar, the initial cracks were propagated at several regions, indicating more vividly the cracks that eventually propagated through the mortar ring wall. As observed, the crack for mortars with hybrid fibre at 'I' becomes the only crack that managed to propagate through

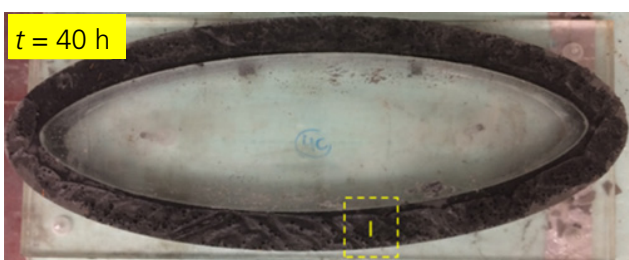

(a)

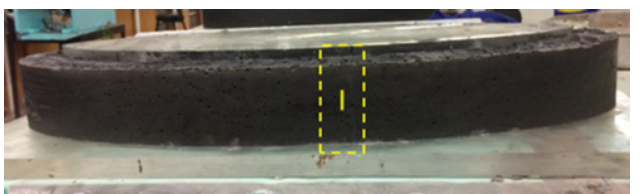

(b)

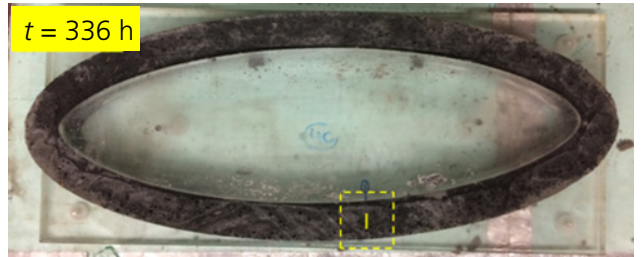

(c)

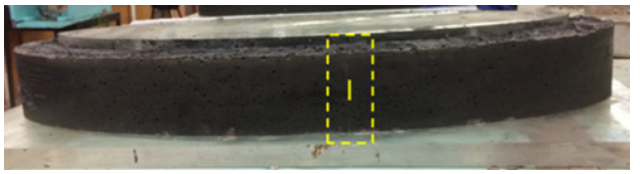

(d)

Figure 12. Crack positions in thin elliptical ring for mixture 90FA_10CH_12M_2.5S/H_1.0A/B_0.2HF: (a) top view of the crack position at the initial time of crack appearance; (b) lateral view of the initial crack position; (c) top view of the crack positions at the final time of test; (d) lateral view of the final crack positions composed of one visible crack placement 


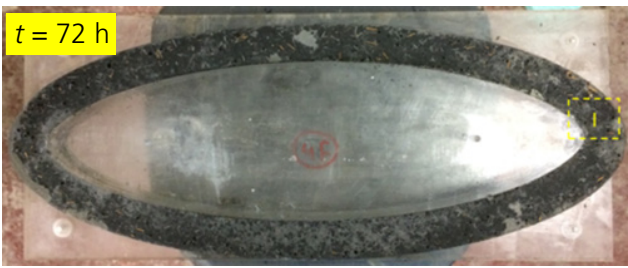

(a)

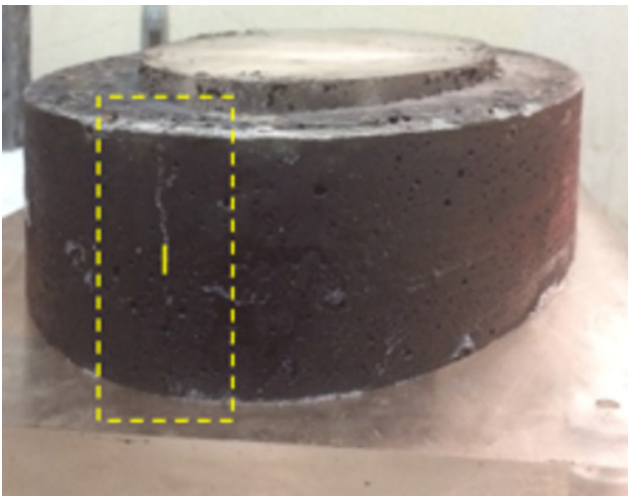

(b)

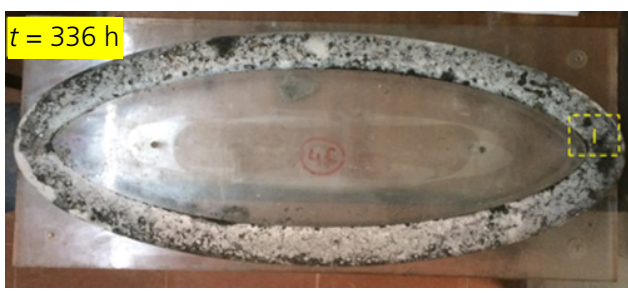

(c)

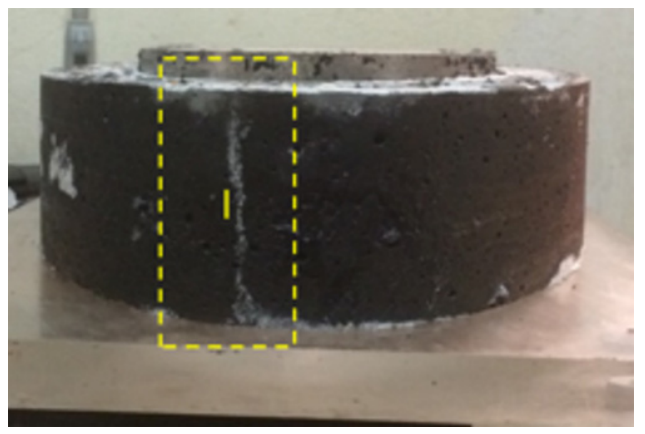

(d)

Figure 13. Crack positions in thin elliptical ring for mixture 90FA_10CH_12M_2·5S/H_1·0A/B_0.8HF: (a) top view of the crack position at the initial time of crack appearance; (b) lateral view of the initial crack position; (c) top view of the crack positions at the final time of test; (d) lateral view of the final crack positions composed of one visible crack placement

the wall of the elliptical ring specimens. The results imply that the crack-driving energy is lower for this specimen with hybrid fibre that requires a higher stress to cause a crack to propagate after it is initiated.

\subsubsection{Initial cracking time}

The initial cracking time of mortars is given in Table 5. From the table, the general effect of SHPF contents on the initial cracking time is clear. Increasing the SHPF content resulted in delaying the initial cracking time of the mortars. It is further noticed that in the mortar with formulation of 90FA_10CH_12M_2.5S/H_1.0A/B_0 $8 \mathrm{HF}$, the initial crack was visible much later than that of the mortar without fibre, which was after $3 \mathrm{~d}$. However, this lag time may necessarily lead to alteration of the crack pattern of the specimen, as shown in Figures 11-13. Comparing the crack pattern

Table 5. Visible initial cracking time of the AACB mortars

\begin{tabular}{lc} 
Formulation & $\begin{array}{c}\text { Visible initial } \\
\text { cracking time: } \approx \mathbf{h}\end{array}$ \\
\hline 90FA_10CH_12M_2.5S/H_1.0A/B_0.0HF & 24 \\
90FA_10CH_12M_2.5S/H_1.0A/B_0.08HF & 30 \\
90FA_10CH_12M_2.5S/H_1.0A/B_0.2HF & 40 \\
90FA_10CH_12M_2.5S/H_1.0A/B_0.8HF & 72 \\
\hline
\end{tabular}

observed for plain and hybrid fibre mortars indicates the clear effect of increasing the SHPF content, and the delay of cracking up to $48 \mathrm{~h}$ for 90FA_10CH_12M_2 5S/H_1 $0 \mathrm{~A} / \mathrm{B} \_0 \cdot 8 \mathrm{HF}$. Furthermore, it is noticed that SHPF reduces the number of cracks along the sample regardless of the incorporated dosage. Of course, the modulus of elasticity of the mixtures also has a direct influence on cracking development, as can be seen in Figure 14.

\subsubsection{Crack width}

The average and ultimate crack width of the restrained ellipse ring is presented in Figures 15 and 16. A content of SPHF as low as $0.08 \%$ was able to reduce the average crack width by four times when compared with non-reinforced mortars. Increasing the content of SPHF from 0.08 to $0.8 \%$ reduced the time of appearance of this first crack by $25 \mathrm{~h}$ and reduced the average crack width by two times. Furthermore, it can be seen that in the plain mortar, the measurement indicates a gradual increase with age followed by a sudden and significant increase in the width of the cracks. As the specimen dries, its shrinkage increases with age. However, enhancing shrinkage of the material is restrained by the central ellipse ring, resulting in an increase of pressure, which is imposed on the central ellipse ring by the surrounding mortar ring. As a result, compressive stress is developed in the central ellipse ring, which becomes 


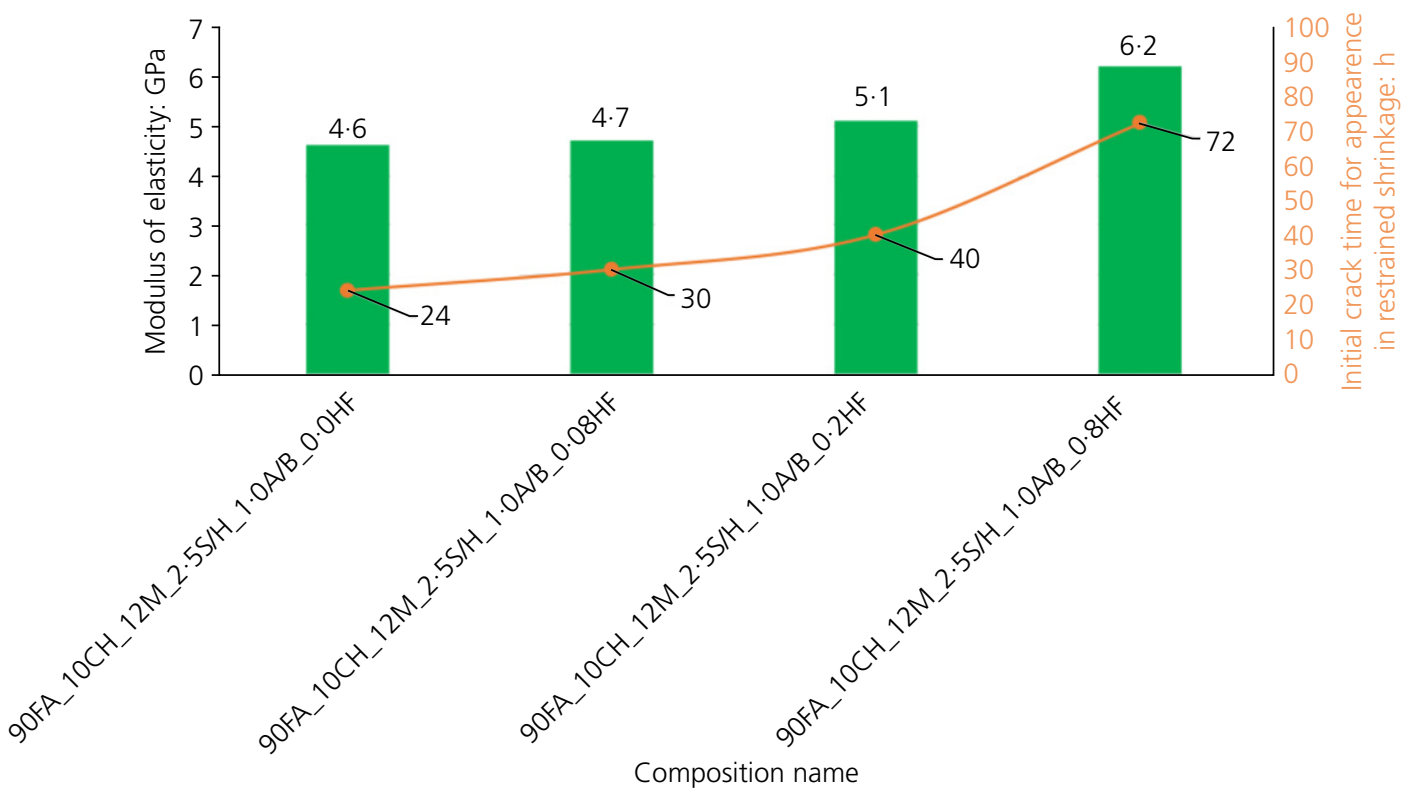

Figure 14. Relationship between the time for initial crack appearance in restrained shrinkage and the modulus of elasticity for mortars with different hybrid fibre content. A full-colour version of this figure can be found on the ICE Virtual Library (www.icevirtuallibrary.com)

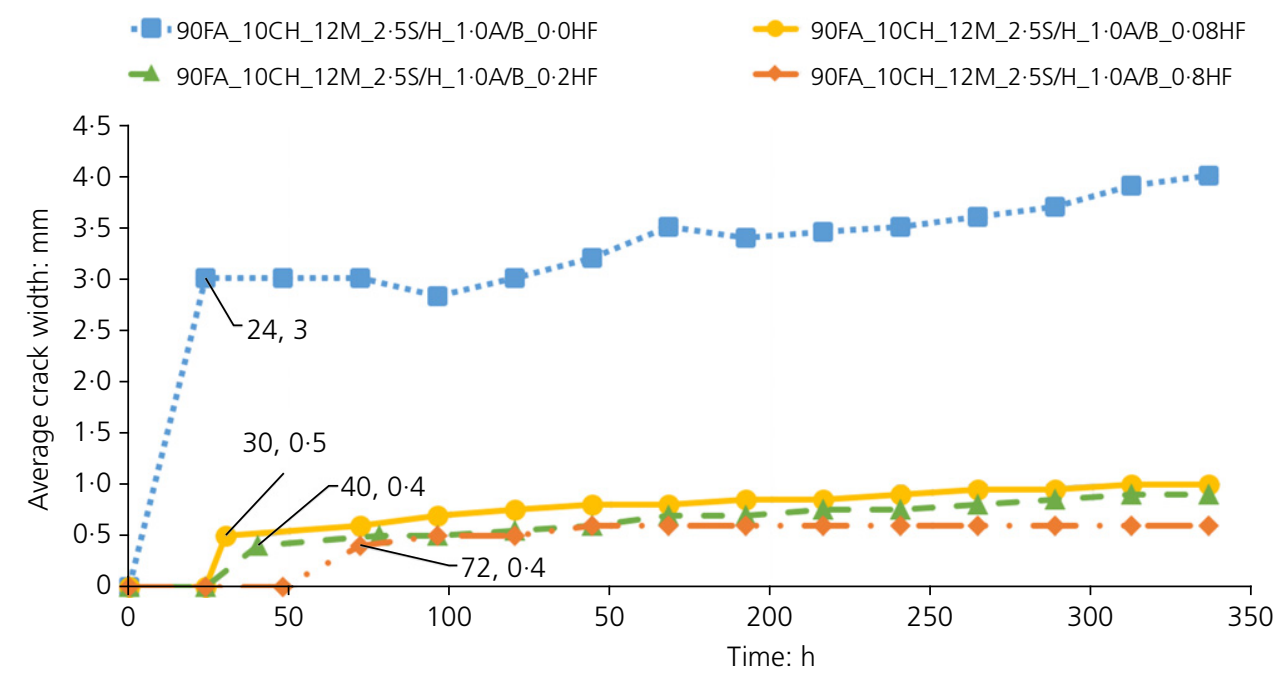

Figure 15. Average crack width for different mortars with different hybrid fibre content

greater and is reflected by the increasing crack width with age. Simultaneously, tensile stress is developed in the mortar ring, which also enhances with age. When the tensile stress exceeds the tensile strength of mortar, a crack initiates and the pressure imposed on the central ring is released, and consequently the stress drops in the central ellipse ring. Figure 17 shows the number of cracks observed in individual tests plotted against the maximum crack width monitored at $14 \mathrm{~d}$ of testing. It was noticed that the effect of SHPF reduced the number of cracks to one-third. Furthermore, the presence of the hybrid fibre indicated a significant reduction in average width crack by more than one-quarter. The higher content of SHPF $(0 \cdot 8 \%)$ is 


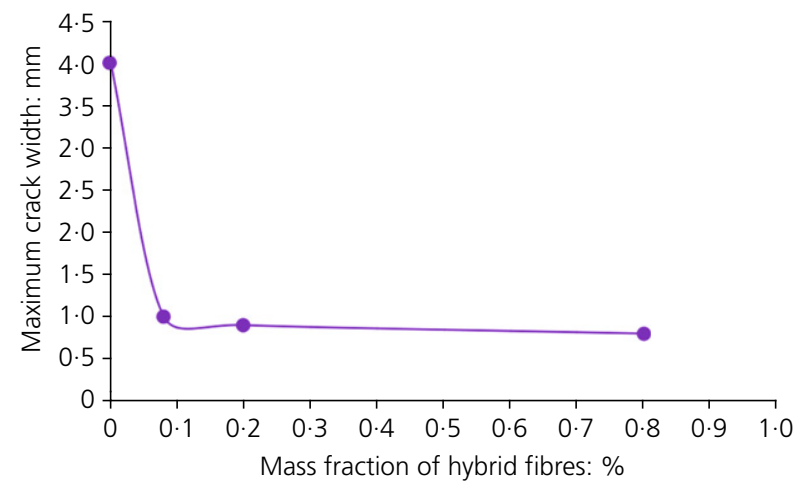

Figure 16. Maximum crack width plotted against hybrid fibre content of mortars more effective in terms of minimising crack appearance (Figure 18).

\section{Microstructure}

Figure 19 shows SEM images of geopolymeric mixtures. A strong bond is detected between the geopolymeric matrix and the fibres, confirming results of other studies (Bhutta et al., 2017). The presence of unreacted fly ash particles as well as fibrous $\mathrm{C}-\mathrm{S}-\mathrm{H}$ is noticed.

\section{Conclusions}

No reduction of unrestrained shrinkage was observed, which could be due to an increase in the pore volume. The results show that hybrid short fibres reduce the restrained shrinkage cracking tendency. A content of short hybrid fibres as low as

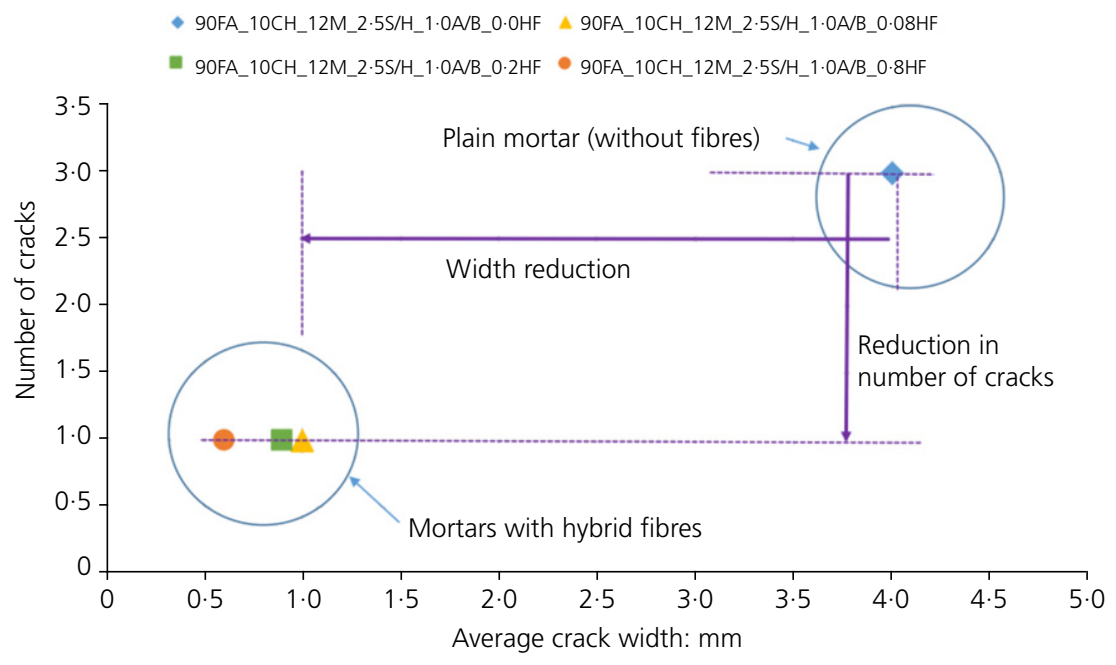

Figure 17. Comparison between plain and hybrid fibre AACB mortars based on crack width and the number of cracks

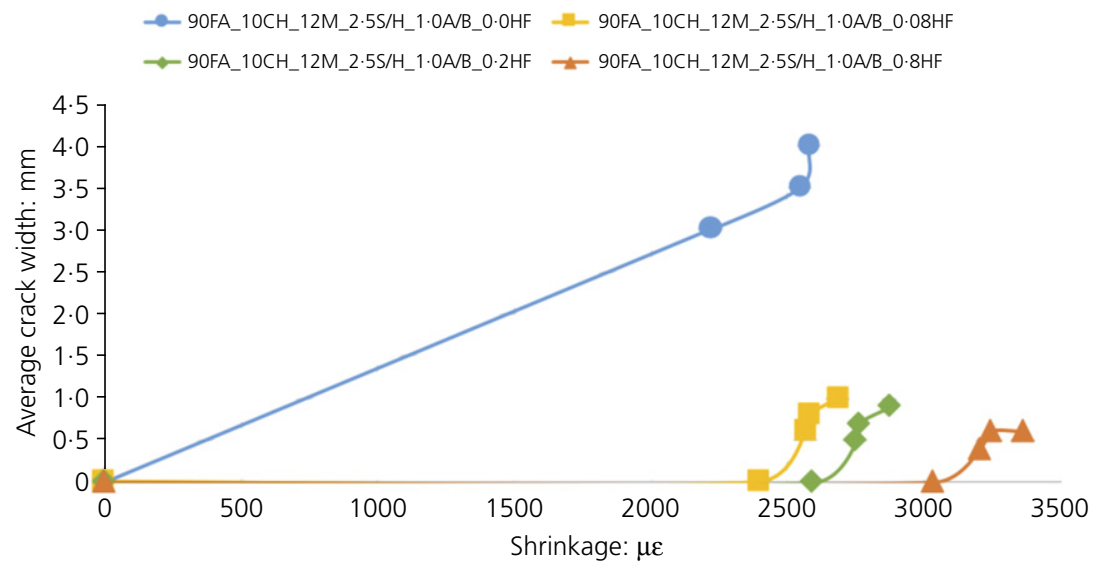

Figure 18. Relationship between average crack width and unrestrained shrinkage for AACB mortars with different hybrid fibre content 
Kheradmand, Abdollahnejad and

Pacheco-Torgal

\section{Offprint provided courtesy of www.icevirtuallibrary.com Author copy for personal use, not for distribution}
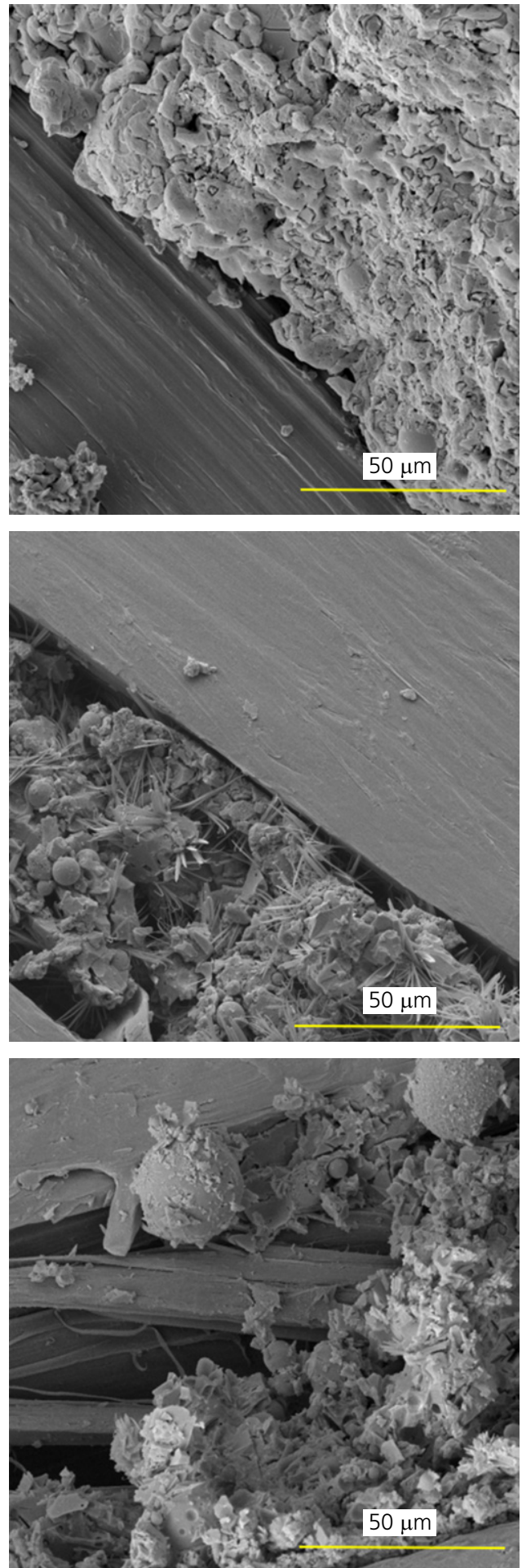

Figure 19. High-resolution SEM image of hybrid fibre in mortars

$0.08 \%$ was able to reduce the average crack width by four times when compared with non-reinforced mortars. Increasing the content of short hybrid fibres from 0.08 to $0.8 \%$ reduced the time of appearance of the first crack by $25 \mathrm{~h}$ and reduced the average crack width by two times.

\section{Acknowledgement}

This study was funded by Foundation for Science and Technology (FCT) in the frame of project IF/00706/2014UM.2 $\cdot 15$.

\section{REFERENCES}

ACAA (American Coal Ash Association) (2016) https://www.acaa-usa. org/Publications/Production-Use-Reports (accessed 06/09/2017).

ASTM (2000) C490: Standard practice for use of apparatus for the determination of length change of hardened cement paste, mortar, and concrete. ASTM International, West Conshohocken, PA, USA.

ASTM (2015) C618-15: Standard specification for coal fly ash and raw or calcined natural pozzolan for use in concrete. ASTM International, West Conshohocken, PA, USA.

Bernal S, Rodríguez E, Kirchheim A and Provis J (2016) Management and valorisation of wastes through use in producing alkali-activated cement materials. Journal of Chemical Technology and Biotechnology 91(9): 2365-2388.

Beushausen $\mathrm{H}$ and Chilwesa M (2013) Assessment and prediction of drying shrinkage in bonded mortar overlays. Cement and Concrete Research 53: 256-266, https://doi.org/10.1016/j.cemconres.2013. 07.008 .

Bhutta A, Farooq M, Zanotti C and Banthia N (2017) Pull-out behavior of different fibers in geopolymer mortars: effects of alkaline solution concentration and curing. Materials and Structures 50(1): 80 .

CEN (European Committee for Standardization) (2014) EN 12390-13: Testing hardened concrete - Part 13: Determination of secant modulus of elasticity in compression. CEN, Brussels, Belgium.

Chindaprasirt P and Cao T (2014) Reuse of recycled aggregate in the production of alkali-activated concrete. In Handbook of AlkaliActivated Cements, Mortars and Concretes (Pacheco-Torgal F, Labrincha J, Palomo A, Leonelli C and Chindaprasirt P (eds)). Woodhead Publishing, Cambridge, UK, pp. 519-538.

Collins F and Sanjayan JG (2000a) Cracking tendency of alkali-activated slag concrete subjected to restrained shrinkage. Cement and Concrete Research 30(5): 791-798.

Collins F and Sanjayan JG (2000b) Effect of pore size distribution on drying shrinkage of alkali-activated slag concrete. Cement and Concrete Research 30(9): 1401-1406.

EC (European Commission) (2014) COM 398 Final. Towards A Circular Economy: A Zero Waste Programme for Europe. Commission to the European Parliament, the Council, the European Economic and Social Committee and the Committee of the Regions, Brussels, Belgium.

Gao X, Yu Q and Brouwers H (2016) Assessing the porosity and shrinkage of alkali activated slag-fly ash composites designed applying a packing model. Construction and Building Materials 119: 175-184, https://doi.org/10.1016/j.conbuildmat.2016.05.026. ISTRICE (2016) http://www.fibreistrice.com/index_en.html (accessed 06/09/2017).

Khan M (2013) Ring test for the measurement of restrained shrinkage of concrete. Applied Mechanics and Materials 377: 86-91, http://dx.doi.org/10.4028/www.scientific.net/AMM.377.86. 
Kristiawan S (2012) Evaluation of models for estimating shrinkage stress in patch repair system. International Journal of Concrete Structures and Materials 6(4): 221-230.

Lee N, Jang J and Lee H (2014) Shrinkage characteristics of alkaliactivated fly ash/slag paste and mortar at early ages. Cement and Concrete Composites 53(2014): 239-248.

Ma Y and Ye G (2015) The shrinkage of alkali activated fly ash. Cement and Concrete Research 68: 75-82, https://doi.org/10.1016/ j.cemconres.2014.10.024.

Mobili A, Belli A, Giosué C, Bellezze T and Tittarelli F (2016) Metakaolin and fly ash alkali-activated mortars compared with cementitious mortars at the same strength class. Cement and Concrete Research 88: 198-210, https://doi.org/10.1016/j.cemconres.2016.07.004.

Pacheco-Torgal F (2014) Introduction. In Handbook of Alkali-Activated Cements, Mortars and Concretes (Pacheco-Torgal F, Labrincha J, Palomo A, Leonelli C and Chindaprasirt P (eds)). Woodhead Publishing, Cambridge, UK, pp. 1-16.

Pacheco-Torgal FP, Aguiar JL, Ding Y, Tahri W and Baklouti S (2015) Performance of alkali-activated mortars for the repair and strengthening of OPC concrete. In Handbook of Alkali-Activated Cements, Mortars and Concretes (Pacheco-Torgal F, Labrincha J, Palomo A, Leonelli C and Chindaprasirt P (eds)). Woodhead Publishing, Cambridge, UK, pp. 627-641.

Pakravan HR, Latifi M and Jamshidi M (2017) Hybrid short fiber reinforcement system in concrete: a review. Construction and Building Materials 142: 280-294, https://doi.org/10.1016/ j.conbuildmat.2017.03.059.

Payá J, Monzó J, Borrachero MV and Tashima MM (2014) Reuse of aluminosilicate industrial waste materials in the production of alkali-activated concrete binders. In Handbook of Alkali-Activated Cements, Mortars and Concretes (Pacheco-Torgal F, Labrincha J,
Palomo A, Leonelli C and Chindaprasirt P (eds)). Woodhead Publishing, Cambridge, UK, pp. 487-518.

Provis JL (2014) Geopolymers and other alkali activated materials: why, how, and what? Materials and Structures 47: 11-25, http://dx.doi. org/10.1617/s11527-013-0211-5.

Ranjbar N, Mehrali M, Behnia A et al. (2016) A comprehensive study of the polypropylene fiber reinforced fly ash based geopolymer. PLoS ONE 11(1): e0147546.

Van Deventer J, Provis J, Duxson P and Brice D (2010) Chemical research and climate change as drivers in the commercial adoption of alkali activated materials. Waste Biomass Valorization 1: 145-155, http://dx.doi.org/10.1007/s12649-010-9015-9.

Van Deventer JSJ, Provis JL and Duxson P (2012) Technical and commercial progress in the adoption of geopolymer cement. Minerals Engineering 29: 89-104, https://doi.org/10.1016/j.mineng. 2011.09.009.

Wallah S and Hardjito D (2014) Assessing the shrinkage and creep of alkali-activated concrete binders. In Handbook of Alkali-Activated Cements, Mortars and Concretes (Pacheco-Torgal F, Labrincha J, Palomo A, Leonelli C and Chindaprasirt P (eds)). Woodhead Publishing, Cambridge, UK, pp. 265-290.

Weiss W and Shah S (2002) Restrained shrinkage cracking: the role of shrinkage reducing admixtures and specimen geometry. Materials and Structures 35(2): 85-91.

Ye $\mathrm{H}$ and Radlinska A (2016) Shrinkage mechanisms of alkali-activated slag. Cement and Concrete Research 88: 126-135, https://doi.org/ 10.1016/j.cemconres.2016.07.001.

Zhuang XY, Chen L, Komarneni S et al. (2016) Fly ash-based geopolymer: clean production, properties and applications. Journal of Cleaner Production 125: 253-267, https://doi.org/10.1016/ j.jclepro.2016.03.019.

\section{How can you contribute?}

To discuss this paper, please email up to 500 words to the editor at journals@ice.org.uk. Your contribution will be forwarded to the author(s) for a reply and, if considered appropriate by the editorial board, it will be published as discussion in a future issue of the journal.

Proceedings journals rely entirely on contributions from the civil engineering profession (and allied disciplines). Information about how to submit your paper online is available at www.icevirtuallibrary.com/page/authors, where you will also find detailed author guidelines. 